\title{
Analysis of Inserted Clauses in the Legal Discourse from the Pragmatic Perspective
}

\author{
Ruzanna Karapetyan (Corresponding author) \\ Romance-Germanic Philology Faculty, Yerevan State University, Alex Manoogian 1, 0025 Yerevan, Armenia \\ E-mail: rkarapetyan@ysu.am \\ Margaret Apresyan \\ Romance-Germanic Philology Faculty, Yerevan State University, Alex Manoogian 1, 0025 Yerevan, Armenia \\ E-mail: apresyan@ysu.am
}

Received: 14-12-2016

Published: 01-07-2017
Accepted: 10-02-2017

doi:10.7575/aiac.ijalel.v.6n.4p.86
Advance Access Published: April 2017

URL: http://dx.doi.org/10.7575/aiac.ijalel.v.6n.4p.86

\begin{abstract}
The aim of the given study is to examine the use of inserted clauses in the legal discourse and their unique role in this speech genre. The investigation of the topic is conducted in line with the principles of Functional Discourse Grammar. In the course of analysis we apply the theory of speech acts, namely performatives, the fundamental tenets of which permit to view the specific combination of shall+inserted clause as a particular feature of legal discourse. These overcomplicated grammatical structures are shown to fulfill the immediate function of performatives, that of enacting legal acts and doing things in the pragmatic sense of word, to the full extent.
\end{abstract}

Keywords: legal discourse, Functional Discourse Grammar, Speech act theory, performatives, inserted clauses, the modal verb "shall"

\section{From Functional Linguistics to the "Professional" Language}

The sophisticated interrelation between the language and human thought and activity is most comprehensively uncovered in the theory of Functional Linguistics. Its investigative apparatus, along with the research principles and methods, is a profound tool which permits to elucidate numerous issues raised and studied in different branches of Linguistics. It proved to be quite reasonable to make accurate conclusions for the problem examined in the given paper as well.

The nature and number of functions realized via the language has always raised debates among linguists. Functions are often viewed along two levels, the first dealing with the generic functions of the language, while the second relating to more specific acts and performances fulfilled by discrete utterances. The two levels are closely connected being integral parts of the same system. They also perform in strict agreement with each other, since the microfunctions of language (realized by discrete utterances) make up the whole system. Conversely, the macrofunctions of the language are accomplished through the language microfunctions.

The role of language functions is different across the levels of analysis. Of special importance to the analysis conducted are the syntactic units of language and the syntactic rules which control their usage. The most significant contribution to the development of language functions and speech styles as predetermined by these functions was made by the representatives of the Prague school, who stressed the function of elements within language (Daneš F.1974, Mathesius V. 1936, Vachek J. 1967, Jakobson R., 1983). According to the linguists of the Prague school styles of language are formed and derive from the specific purpose of the utterance and represent the style function.

The concept of "special" or "professional" language is also based on the elaboration of the Prague school linguists whose hallmark was to view the language in terms of its functions and to analyze the language with the perspective of demonstrating respective functions which various structural components play in the use of the language as an entire system (The theses of the Prague Linguistic Circle, ed. Kondrashov N.A., M, 1967). They adhered to the notion that language is a semiotic system and its main characteristic feature is functionality. Language possesses a wide array of structural means at different strata which are applied appropriately for the realization of this or that function. It is to be noted that the variety of peculiarities of functional means are incompatible, hence the concept of "professional" or "special" language comes forth. Still in the $19^{\text {th }}$ century some linguists considered this issue; the analysis unfolded and was widely examined already in the $20^{\text {th }}$ century. For example A. Schirmer in his work "Die Erforschung der deutschen Sondersprachen" provided the definition of the "professional" language "... I name the specific terminology used in different domains of human activity (such as law and politics, art and science) professional language". When analyzing the concept of "professional" language, some linguists rely on the stylistic peculiarities of the professional texts examined (Shcherba L., 1957; Muller F, 1995). It is also viewed as a subtype of the general language serving the 
cognition processes (Mohn D., 1984). Hoffman L. describes "professional" language as an entity of language means used in the constrained domain of professional communication directed at the optimal mutual understanding of specialist (Hoffman L., 1995).

Analysis of the appropriate literature permits to single out common peculiarities specific of the "professional" language such as:

- close connection to the corresponding scientific field,

- unique array of language means,

- combinatory use of general language means and special language means as preconditioned by the demands of the specific domain,

- tendency for regularities on all language strata,

- written and oral variants.

Of significant importance is the fact that the peculiarities specific of this or that "professional" language are reflected in all the language strata of linguistic analysis. In the paper the syntagmatic relations of logic and dependency comprise the scope of our interest; hence the study is based on the syntactic organization of "professional" texts in Law.

\section{The Language of Law as a Subtype of the "Professional" Language}

The origin of law is closely connected with the origin of language; it is reflected in language and cognized via language. Current work of linguists in the field of Law initiated new interdisciplinary branch of research, specifically Forensic Linguistics or the Language of Law. The primary area of investigation of this discipline is the interrelation between Law and Language. The indivisible link between these two domains was noted in the works of a number of linguists (Bungarten Th., 1993; Engberg J., 1993; Melinkoff D., 1963). As claimed by certain specialists the legal language not only serves to the law, but also affects its content. Other linguists account for the interrelation of Law and Language by their structural affinity. Both systems are based on the compilation of rules, grammatical and legal appropriately (Melinkoff D., 1963).

The study of legal language reveals its affinity with the general language which makes the legal language quite open and flexible. This intermediate position of the language of law between the general and professional subtypes of language complicates its linguistic description. Language of Law is not a "professional" language in the strict sense; thus it has not been fully investigated. However the specific character of the language of law which draws a clear demarcation line between the general language and the language of law is cited in a number of works. For example, $\mathrm{L}$. Thorne McCarty writes: "There are many common sense categories underlying the representation of a legal problem domain: space, time, mass, action, permission, obligation, causation, purpose, intention, knowledge, belief, and so on. The idea is to select a small set of these common sense categories, the ones that are most appropriate for a particular legal application, and then develop a knowledge representation language that faithfully mirrors the structure of this set. The language should be formal: it should have a compositional syntax, a precise semantics and a well-defined inference mechanism" (L. Thorne McCarty, 1976:1)

Language of Law is a broad category involving all the areas of Law with all the specific features. Extralinguistic factors, in this case the peculiarities of the legal practice, account for the linguistic features of law texts. The consideration and analysis of the professional legal language can be trustworthy only in case the unvarying interconnection of legal practices and legal language is taken into consideration. Law is "...a product of and dependent on language, therefore there seems a mutual reflection of law and language through different devices of law and language which create inseparable, immutable and special relationship between language and law (Frederick Shauer, Edn., Law and Language, 1993).

Text being the ultimate product of language means for the realization of various extralinguistic purposes, it is feasible to examine linguistic units of all the language strata in the framework of a coherent text. From the semantic/structural perspective text is a systematic chain of sentences involving various lexical, grammatical and logical links (Kukharenko V.A., 1998).

Special texts are the manifestation of special/professional language, which is an outcome of the narrow professional activity and a tool to tackle professional issues (Hoffman L., 1995). Quite influential contribution into the investigation of special texts was made by Glaser, who elaborated the notion of text types (Glaser R., 1990). A text type is a specific linguistic pattern in which fixed formal and structural characteristics are used to achieve similar purposes. The German linguist R. Glaser expounds on the interrelation between the text type and the functional style and defines the professional style, considered as a subtype of the functional style, as a compilation and regularity of linguistic means dependent on and predetermined by the utterance purpose, content and for (Gaser, 1990:26). For the analysis of professional texts German linguist L.Hoffman proposes the accumulative method of investigation wherein the comprehensive consideration of the elements of all language strata is presupposed. As a result of such analysis a general network of the elements of all the strata and their interrelation is obtained (Hoffman L., 1995, 237).

Since any profound investigation calls for the systematic and consecutive analysis of elements with the aim of constructing a reliable ultimate picture of the system, in the paper we will study the phenomenon of inserted phrases and clauses in the language of Law texts. This will enable to reveal certain regularities and validity in the use of these complex syntactic units. Proceeding from the fact that any genre is an orderly system of interconnected linguistic units based on the functional perspectives of the genre, the peculiar use any particular linguistic unit in the light of its regularities is hypothesized to witness of the specificity and unique niche of this or that genre in the language as a 
general system. Thus, this particular study of a particular linguistic unit is a single brick in the genre formation edifice of the Language of Law which is to be augmented by the consideration of other units for the construction for a complete picture.

\section{Inserted Phrases and}

\subsection{Inserted Clauses from the Functional Theory Perspective}

The grammatical phenomenon of the inserted clause is an insufficiently investigated category, which, nonetheless, plays a key role, in legal texts particularly, from the pragmatic and functional point of view. One of the characteristics of the inserted clauses is that they are very loosely defined due to having fundamental structural and semiotic affinity to the parenthetical clauses. Like the parenthetical clauses they are usually inserted into a longer string and their relation to the main clause often has the nature of supplement. From the perspective of the given study, it is worth mentioning that inserted clauses come to disrupt the smooth course of speech and interrupt the legal thought unfolding, at the same time constituting a single unit with the main clause, both structurally and semantically. This characteristic feature and a high frequency of use of these linguistic units in the legal speech could be accounted for by the laws of Functional Discourse Grammar, a branch of theoretical linguistics drawing upon the tenets of Functional linguistics and at the same time incorporating the principles and regularities of discourse study. More specifically " the main goal of Functional Discourse Grammar is to give an account of morphosyntactically and phonologically codified phenomena in languages, either as correlated with pragmatic or semantic aspects of Formulation or as displaying inherent properties of Encoding. In the former 6 case, the phenomenon is functionally motivated; in the latter case, it is arbitrary. As the name of the theory suggests, the emphasis in FDG work is strongly on the former. The functionalist stance entails the hypothesis that a wide range of formal categories can be insightfully explained if they are brought into correspondence with semantic and pragmatic categories rooted in human cognition and interhuman communication" (Hengeveld, 2009:315). In other words, under the umbrella of Functional Discourse Grammar the interplay of the form and function is placed in the forefront of linguistic investigations and the answers are sought on the halfway between the formal and functional perspectives of the language analysis with the emphasis on the latter.

As applied to the study below, it could be stated that the specificity of the legal discourse is both governed by and manifested in its semantic and pragmatic predetermination, as well as its functionality. The extensive use of the inserted clauses in the legal discourse is mainly justified by the points mentioned above. In the paragraph to follow we make an attempt to describe and analyze the role of this linguistic phenomenon from the perspective of functional discourse principles. The Declaration of Independence and the Constitution of the United States served as an empirical material and a starting point for our analysis.

3.2 The Role and Meaning of Inserted Phrases and Clauses in Legal Discourse (Study Based on the Analysis of the Declaration of Independence and the Constitution of the USA)

It is often difficult to integrate inserted clauses into the general grammatical description of the sentence. In dealing with the inserted clause traditional grammars mainly dwell upon its position in the linear order of the sentence and correlation with the elements of the main clause. In the given study we rely upon the definition of the inserted clause provided by Forget D: “...to be considered an inserted clause, the clause has to a) interrupt the main clause; b) but at the same time be in cohesion (in the sense of "underlying semantic relation") with the main clause and/or the linguistic context in which it is inserted" (Forget D., 1992:374). The scholar indicates the "mobility" and "autonomy" of these clauses as their primary characteristic feature. Although bearing significant semantic meaning and supplementing the compositional structure of the sentence, it also demonstrates a high level of autonomy in that "the main clause counts in itself as a grammatical sentence; as a consequence, the inserted clause can be deleted without affecting the main clause" (Forget D., 1992:375). It looks more likely that the inserted clauses are not as much in relation with certain elements of the main clause but with the main clause itself fulfilling specific functions and in certain contexts having pragmatic directionality. In other words, there are sentences in which elements of simple sentences are moved from their canonical positions to fulfill certain functions.

In different genres of the legal speech various purposes and functions served by the law in society are realized via corresponding linguistic units. Within the framework of the given research we make an attempt to investigate the specific functions performed by inserted clauses in the genre of legal discourse, as well as the regularities of their use. Particularly we studied "the Declaration of Independence and the Constitution of the United States" and below present certain observations and comments on the issue discussed.

Let us consider the following sentences:

1. No Senator or Representative shall, during the Time for which he was elected, be appointed to any civil Office under the Authority of the United States, which shall have been created (13).

2. Every Bill which shall have passed the House of Representatives and the Senate, shall, before it become a Law, be presented to the President of the United States (13).

3. Each State shall appoint, in such Manner as the Legislature thereof may direct, a Number of Electors, equal to the whole Number of Senators and Representatives to which the State may be entitled in the Congress (18).

In the sentences above certain grammatical elements, specifically subordinate clauses of time $(1,2)$ and manner $(3)$ are displaced from their conventional linear position in the sentence. They are interposed into the coherent flow of thought development in a mechanical way via the detachment of the traditional grammatical sentence structure. It should be 
noted that the cases of such displacement are quite frequent in the material analyzed. To be more specific, per page the average number of inserted clauses is 5-6. Such frequent use of these unconventional structures is definitely preconditioned by the specificity of the legal genre which in the long run also dictates the rules for the linguistic formulation of its content.

As is known law, consequently legal texts, create, formulate and modify the rights, obligations, norms of behavior and the unanimously accepted code of functioning of institutions and individuals. This is the utmost function of law which guarantees the legal and sustainable existence and development of any society. From the pragmatic perspective and in terms of J. Austin the functions of the law mentioned above are referred to as performatives (Austin J. 1962). Wardhaugh R. writes on performatives: "In using a performative utterance, a person is not just saying something but is actually doing something if certain real-world conditions are met" (Wadhaugh, 2006: 285).

Legal discourse, as a type of authoritative writing, aims at carrying out certain functions, which in general is labeled by Fiorito L. as "doing lawful things with words" (Lorenzo, 2006: 101). As evidenced in the same paper by Fiorito L., most of the speech acts in legal discourse fall under the category of performatives, which are meant to carry out legal acts rather than doing speech acts (Fiorito, 2006: 101). Hence, these speech acts are correspondingly expressed via language units. In the material we analyzed the modal verb shall is frequently used in combination with the inserted clauses. As is known in the legal discourse the modal verb preserved its original meaning of giving command and instructions. In other words, we could conclude that shall is a natural and, thus, mostly frequent way of "doing lawful things with words", or enacting performatives. The frequent combination of the modal verb shall (as fulfilling the role of performatives' formulation)

with the inserted clauses is a specific feature of the legal discourse. It is observed that that this kind of combination also purports particular goals. According to the rules of the Functional discourse grammar the change in the conventional word order in the sentence is closely related with the theme-rheme phenomenon. In the case analyzed we can state that the semantic loading of the sentences 1-3 is magnified due to this combination of shall and the inserted clauses, which adds weight to the information conveyed and ensures the perlocutionary effect of the utterance. The sentences provided above are not unique cases in the material we analyzed, but comprise a significant fraction of it. To be more specific, on the average 5 examples of this type are used per page in the material studied.

In the course of study there were encountered more sophisticated cases of the shall and inserted clause combination. Let us resort to the following sentences:

4. We the people of the United States, in Order to form a more perfect Union, establish Justice, insure domestic Tranquility, provide for the common defence, promote the general Welfare, and secure the blessings of Liberty to ourselves and our Posterity, do ordain and establish this Constitution for the United States of America (9).

5. The Congress, whenever two thirds of both Houses shall deem it necessary, shall propose Amendments to this Constitution, or, on the Application of the Legislatures of two thirds of the several States, shall call a Convention for proposing Amendments, which, in either case, shall be valid to all Intents and Purposes, as Part of this Constitution, when ratified by the Legislatures of three fourths of the several States, or by Conventions in three fourths thereof, as the one or the other Mode of Ratification may be proposed by the Congress. (25)

6. The Conventions of a number of the States, having at the time of their adopting the Constitution, expressed a desire, in order to prevent misconstruction or abuse of its powers, that further declaratory and restrictive clauses should be added (30).

In the examples above multiple use of such complicated linguistic units within the frame of a single sentence can be reported, which is definitely a very specific discourse-preconditioned phenomenon.

In conclusion, it can be stated that the use of atypical sentence structure, like conjoined sentences, repetitions, overcomplicated subordinates and in the given case inserted clauses in combination with the modal verb shall, is a weighty argument to pattern legal discourse as a specific genre.

\section{References}

Austin J. (1962). How to Do Things with Words. Oxford, Clarendon Press.

Bhatia K. (2010). Textbook on Legal Language and Legal Writing. New Delhi.

Bungarten Th. (1993) Hinsichten ru einer Theorie von Fachsprachen. Zur Einfuhrung. //Fachsprachentheorie: FST (betreut und hrsg). Von Theo Bungarten, Tosted, Attikon, Bd.

Daneš F., ed. (1974). Papers on Functional Sentence Perspective. Academia Praha.

Engberg J. (1993). Prinzipen einer Typologisierung jurisiticher Texte. Fachsprache, international journal of LSP jg. 15.H.1.-2.

Fiorito L. (2006). On Performatives in Legal Discourse. Metalogicon (2006) XIX, 2.

Forget D. A. (1992). Pragmatic Role for Inserted Clauses in Literary Texts. Cooperating with Written Texts. The Pragmatics and Comprehension of Written Texts, ed.by Dieter Stein, pp. 373-395, Mouton de Gruyter.

Hengeveld Kees \& Mackenzie Lachlan (2009). Functional Discourse Grammar. The Oxford Handbook of Linguistic Analysis, ed. by Bernd Heine and Heiko Harrog. Oxford. 
Hoffman L. (1995). Intraserielle und interserielle Vergleiche von Fachtexten. Ein Beitrag zur Unterscheidung von Textsorten. Munchen.

Jakobson R. (1983). Dialogy (Dialogues between Roman Jakobson and Kristina Pomorska). Český spisovatel Praha. Kukharenko V.A. (1998). Text Interpretation. Moscow.

Mathesius V. (1936). On Some Problems of the Systematic Analysis of Grammar. TCLP 6, 95-107.

L. Thorne McCarty (1989). A Language for Legal Discourse: Basic Features, published in ICAIL '89 Proceedings of the 2nd international conference on Artificial intelligence and law", pp. 180-189.

Melinkoff D. (1962). The language of Law. Boston, Little, Brown and Co.

Mohn D., Pelka R. (1984) Fachsprachen Nubingen: Niemyer.

Muller F. (1995). Juristiche Methodik. Berlin: Duncker \& Humboldt.

Schimer, Alfred (1913). Die Erforschung der deutschen Sondersprachen, in: Germanisch-Romanische Monatsschrift, 5, $1-22$.

Shcherba L. (1957). Selected Works in the Russian language. Moscow.

Vachek J. (1967). A Prague School Reader in Linguistics. Indiana U.P. Bloomington London.

Wardhaugh R. (2006). An Introduction to Sociolinguistics. Blackwell Publishing. 